\title{
Pathophysiology of Locus Ceruleus Neurons in a Mouse Model of Rett Syndrome
}

\author{
Praveen Taneja, ${ }^{1 *}$ Michael Ogier, ${ }^{2 \star}$ Gabriel Brooks-Harris, ${ }^{3}$ Danielle A. Schmid, ${ }^{2}$ David M. Katz, ${ }^{2 *}$ and Sacha B. Nelson ${ }^{1 *}$ \\ ${ }^{1}$ Department of Biology and National Center for Behavioral Genomics, Brandeis University, Waltham, Massachusetts 02454, ${ }^{2}$ Department of Neurosciences, \\ Case Western Reserve University School of Medicine, Cleveland, Ohio 44106, and ${ }^{3}$ Department of Biology, Program of Neuroscience and Behavior, \\ Wesleyan University, Middletown, Connecticut 06459
}

Rett syndrome (RTT) is a neurodevelopmental disorder caused by loss-of-function mutations in the Methyl-CpG-binding protein-2 (MECP2) gene and is characterized by derangements in cognition, behavior, motor control, respiration and autonomic homeostasis, as well as seizures. Deficits in norepinephrine (NE) are thought to contribute to RTT pathogenesis, but little is known about how MeCP2 regulates function of noradrenergic neurons. We therefore characterized morphological, electrical, and neurochemical properties of neurons in the locus ceruleus (LC), the major source of noradrenergic innervation to the central neuraxis, in Mecp2 mutant mice. We found that MeCP2 null LC neurons are electrically hyperexcitable, smaller in size, and express less of the NE-synthesizing enzyme tyrosine hydroxylase (TH) compared with wild-type neurons. Increased excitability of mutant neurons is associated with reductions in passive membrane conductance and the amplitude of the slow afterhyperpolarization. Studies in Mecp2 heterozygotes, which are mosaic for the null allele, demonstrated that electrical hyperexcitability and reduced neuronal size are cell-autonomous consequences of MeCP2 loss, whereas reduced TH expression appears to reflect both cell-autonomous and non-autonomous influences. Finally, we found reduced levels of TH and norepinephrine in cingulate cortex, a forebrain target of the LC. Thus, genetic loss of MeCP2 results in a somewhat paradoxical LC neuron phenotype, characterized by both electrical hyperexcitability and reduced indices of noradrenergic function. Given the importance of the LC in modulating activity in brainstem and forebrain networks, we hypothesize that dysregulation of LC function in the absence of MeCP2 plays a key role in the pathophysiology of RTT.

\section{Introduction}

Rett syndrome (RTT) is a neurodevelopmental disorder caused by loss of function mutations in the X-linked gene encoding Methyl-CpG-binding protein-2 (MeCP2) (Amir et al., 1999). Most RTT patients are heterozygous (HET) females and develop normally for 6-18 months of age before the onset of cognitive, motor, and behavioral deficits, including stereotypical hand movements, loss of speech, and autistic features, as well as seizures and severe disturbances of breathing, cardiorespiratory integration, and gastrointestinal function (Hagberg et al., 1983; Chahrour and Zoghbi, 2007; Ogier and Katz, 2008). Although males rarely present with classical RTT, hemizygous males carrying mutations

\footnotetext{
Received July 2, 2009; accepted Aug. 17, 2009.

This work was supported by grants from National Institute of Neurological Disorders and Stroke and the International Rett Syndrome Foundation (D.M.K., S.B.N.). We acknowledge the contribution of the Neurochemistry Core, which is funded by National Institute of Child Health and Human Development Grant P3O HD15052, and the Center for Molecular Neuroscience at the Vanderbilt University Medical Center. We thank Dr. Qifang Wang and Zhe Meng for their help with maintenance and genotyping of the mouse colonies and Saori Kato for her help with immunohistochemistry. P.T. conducted the electrophysiology measurements and analyses. P.T. M.O., and G.B.H. conducted the soma size measurements and analyses. M.O. conducted the measurements and analyses of TH and NE expression in LC and cingulate cortex. M.O. and D.A.S. conducted the cell counts and analysis. P.T., M.O., D.M.K., and S.B.N. designed the experiments and wrote this manuscript.

*P.T. and M.0. are equal coauthors.

\#D.M.K. and S.B.N. are equal senior authors.

Correspondence should be addressed to Sacha B. Nelson, Department of Biology and National Center for Behavioral Genomics, Brandeis University, 415 South Street, Waltham, MA 02454. E-mail: nelson@brandeis.edu. D0I:10.1523/JNEUROSCI.3156-09.2009

Copyright $\odot 2009$ Society for Neuroscience $\quad$ 0270-6474/09/2912187-09\$15.00/0
}

in $M E C P 2$ have related but more severe symptoms, including hypotonia, movement disorders, reduced head growth, and severe respiratory disturbances that typically lead to death soon after birth (Schule et al., 2008).

Levels of biogenic amines, including norepinephrine (NE), are lower in the brain tissue of RTT patients (Zoghbi et al., 1989) and in mouse models of the disease (Ide et al., 2005), and NE deficiency has been associated with irregular and depressed breathing in Mecp2 mutant mice (Viemari et al., 2005). These observations indicate a deficit in NE signaling in RTT, but the impact of MeCP2 loss on NE neuronal function has not been defined. In normal animals, NE released from locus ceruleus (LC) neurons has been shown to regulate diverse CNS functions that are disrupted in RTT, including respiratory motor output (Funk et al., 1994; Adachi et al., 2005), seizure threshold (Bengzon et al., 1999), and cortical synaptic plasticity (Gelinas and Nguyen, 2005; Hu et al., 2007; Seol et al., 2007). Because LC is one of the primary sources of NE in the brain, and the exclusive source of noradrenergic input to cortex and hippocampus (Berridge and Waterhouse, 2003), and because abnormal LC function has been postulated recently to underlie behavioral abnormalities common to autism spectrum disorders, including RTT (Mehler and Purpura, 2009), we decided to investigate the effects of Mecp2 mutation on the functional, morphological, and neurochemical properties of LC neurons. Indeed, our results indicate that genetic loss of MeCP2 results in cell-autonomous and non-autonomous alterations in the morphological, electrophysiological, and neurochemical proper- 
ties of LC neurons, including reduced cell size, electrical hyperexcitability, and decreased indices of noradrenergic function.

\section{Materials and Methods}

\section{Animals used}

Three groups of animals were used in this study: (1) Mecp $2^{\text {tml.1Jae }}$ mice (Chen et al., 2001) backcrossed with C57BL/6 mice ( $>10$ generations), (2) Mecp $2^{\text {tm 1.1Jae }}$ mice backcrossed with C57BL/6 mice ( $>10$ generations) expressing the green fluorescent protein (GFP) under the control of the tyrosine hydroxylase (TH) promoter (THGFP mice) (Matsushita et al., 2002), and (3) Mecp $2^{\text {tm1.1Jae }}$ mice maintained on a mixed background (sv129, BALB/c, C57BL/6). All animal procedures were conducted in accordance with National Institutes of Health guidelines and were approved by the Animal Care and Use Committees at Brandeis University and Case Western Reserve University.

\section{Electrophysiology}

Tissue preparation. Mice [postnatal day 26 (P26) to P28] were briefly anesthetized with isoflurane and decapitated, and the brains were quickly removed and placed in ice-cold artificial CSF (ACSF). Horizontal 300 $\mu \mathrm{m}$ sections containing the LC were made using a vibratome (VT1000S; Leica Microsystems) and allowed to recover at $33-35^{\circ} \mathrm{C}$ for $20 \mathrm{~min}$, followed by incubating a minimum of $1 \mathrm{~h}$ at room temperature $\left(\sim 20^{\circ} \mathrm{C}\right)$ in ACSF. The ACSF contained the following: $126 \mathrm{~mm} \mathrm{NaCl}, 25 \mathrm{~mm}$ $\mathrm{NaHCO}_{3}, 2.5 \mathrm{~mm} \mathrm{KCl}, 1.2 \mathrm{~mm} \mathrm{NaH} \mathrm{PO}_{4}, 2.1 \mathrm{~mm} \mathrm{CaCl}, 1 \mathrm{~mm} \mathrm{MgCl}$, and $32.6 \mathrm{~mm}$ dextrose, osmolality of $326 \mathrm{mOsm}, \mathrm{pH} 7.4$, continuously bubbled with $95 \% \mathrm{O}_{2} / 5 \% \mathrm{CO}_{2}$.

Recordings. The slices were transferred to a submersion style recording chamber and continuously perfused with $\mathrm{ACSF}\left(\right.$ at $\left.32^{\circ} \mathrm{C}\right)$. Neurons were visualized using a $40 \times$ water-immersion objective (numerical aperture 0.80 ) under transmitted light using an upright microscope (Olympus BX50 WI). The LC was identified by its translucent appearance and proximity to the fourth ventricle. The identity of LC neurons was confirmed in slices that were stained post hoc for biocytin and TH. Whole-cell current-clamp recordings were performed using glass micropipettes having a tip resistance of $4-6 \mathrm{M} \Omega$ and filled with the following internal solution: $20 \mathrm{~mm} \mathrm{KCl}, 100 \mathrm{~mm}$ K-gluconate, $10 \mathrm{~mm}$ HEPES, $4 \mathrm{~mm} \mathrm{Mg-}$ ATP, $0.3 \mathrm{~mm} \mathrm{Na-GTP,} 10 \mathrm{~mm}$ Na-phosphocreatine, and $0.2 \%$ biocytin, osmolality of 300 mOsm, pH 7.35 using $\mathrm{KOH}$ ). The liquid junction potential was calculated to be $\sim 14 \mathrm{mV}$ (pipette negative relative to bath) and was left uncorrected. To isolate the changes in intrinsic membrane properties from changes in synaptic inputs, we performed the recordings in synaptic blockade. AMPA, NMDA, and $\mathrm{GABA}_{\mathrm{A}}$ receptor blockers were added to the ACSF at the following concentrations (in $\mu \mathrm{M}$ ): 20 DNQX, 100 DL-APV, and 50 picrotoxin. Contribution of SK channels (small-conductance calcium-activated potassium channels) to neuronal excitability was isolated by bath application of apamin (100 nM). All drugs were purchased from Sigma-Aldrich. In most cases, the neurons were spontaneously active after the whole-cell current-clamp configuration was established. Neurons were hyperpolarized to a subthreshold voltage of $-60 \mathrm{mV}$ by injecting a small, constant, negative current, and the relationship between firing frequency and injected current (FI curve) and other repetitive firing properties were measured during $1 \mathrm{~s}$ current steps. Interstimulus intervals (ISI) of $20 \mathrm{~s}$ allowed neurons to recover from strong afterhyperpolarizations (AHP) after each spike train. Data were acquired using Multiclamp 700A amplifiers (Molecular Devices) and was low-pass filtered (Butterworth) at $21 \mathrm{kHz}$ before digitizing at 10 $\mathrm{kHz}$. Aliasing introduced by this high filtering frequency was measured and found to be negligible (amplitude of aliasing noise, $<50 \mathrm{nV}$ mean and $<150 \mathrm{nV}$ root mean square).

Analysis. Electrophysiological analyses were performed using customwritten software in Igor Pro 6.03A (WaveMetrics). Recordings were excluded if the series resistance (uncompensated) was $>25 \mathrm{M} \Omega$ (or changed by more than $20 \%$ ) or the membrane resistance was $<100 \mathrm{M} \Omega$, or the membrane voltage was more than $-57 \mathrm{mV}$ or less than $-63 \mathrm{mV}$ after recovery from firing. Action potential voltage threshold was defined as the point at which $\mathrm{dV} / \mathrm{dt}$ exceeded $10 \mathrm{~V} / \mathrm{s}$. The AHP after individual spikes was measured as the difference between membrane voltage before the spike voltage threshold and the voltage minimum after the spike.
Similarly, the poststimulus AHP (psAHP) was measured as the difference between membrane voltage before current injection and the minimum voltage in a $2 \mathrm{~s}$ window after the end of the stimulus. The amplitude and decay time constants for the biexponential decay of the psAHP were calculated by fitting exponentials from $100 \mathrm{~ms}$ after the psAHP minimum to $800 \mathrm{~ms}$ after the end of current stimulus and from 3 to $14.5 \mathrm{~s}$ after the end of the current stimulus.

\section{Immunohistochemistry}

Tissue preparation. Mice (P26-P50) were anesthetized by intraperitoneal injection $(200 \mathrm{mg} / \mathrm{kg}$ ketamine, $25 \mathrm{mg} / \mathrm{kg}$ xylazine, and $5 \mathrm{mg} / \mathrm{kg}$ acepromazine) and perfused intracardially with $4 \%$ paraformaldehyde. Brains were extracted, postfixed in $4 \%$ paraformaldehyde for $2 \mathrm{~h}$, and then transferred to PBS. Sagittal sections, $50 \mu \mathrm{m}$, were prepared on a vibratome and stored in $\mathrm{PBS}$ at $-80^{\circ} \mathrm{C}$ until further use.

Immunolabeling. Free-floating sections were permeabilized and blocked for $2 \mathrm{~h}$ at room temperature in $0.3 \%$ Triton X-100 and $10 \%$ serum in PBS and then incubated for $15 \mathrm{~h}$ at $4^{\circ} \mathrm{C}$ in primary antibody. Primary antibodies were used at the following concentrations: mouse monoclonal anti-TH ( $1 \mu \mathrm{g} / \mathrm{ml}$; EMD Chemicals); chicken polyclonal anti-TH ( $1 \mu \mathrm{g} / \mathrm{ml}$; Aves Labs); rabbit polyclonal anti-MeCP2 $(0.5 \mu \mathrm{g} / \mathrm{ml}$; Millipore Corporation). Secondary antibodies were used at the following concentrations: Alexa Fluor 488 goat anti-mouse IgG ( $4 \mu \mathrm{g} / \mathrm{ml}$; Invitrogen); cyanine 3-donkey anti-chicken $\operatorname{IgG}(5 \mu \mathrm{g} / \mathrm{ml}$; Jackson ImmunoResearch); and Alexa Fluor 568 goat anti-rabbit IgG (4 $\mu \mathrm{g} / \mathrm{ml}$; Invitrogen). For labeling biocytin and MeCP2 in neurons in thick slices $(300 \mu \mathrm{m})$ used for electrophysiology, the Triton X-100 concentration was increased threefold, and secondary antibody incubation and wash times were doubled. Biocytin was detected with cascade blue-conjugated Neutravidin $(0.5 \mu \mathrm{g} / \mathrm{ml}$; Invitrogen $)$, and the concentration of MeCP2 primary antibody was doubled. TH levels in the LC and cingulate cortex were determined by densitometric analysis of brain sections immunostained for TH. For cell count experiments, sections were stained with TH and 4',6-diamidino-2-phenylindole to label cell nuclei.

Soma size imaging and analysis. Slices were imaged with a laser scanning confocal microscope (Leica TCS SP2; Leica Microsystems) using a $40 \times$ oil-immersion objective (numerical aperture, 1.25). Serial optical sections were taken at $1 \mu \mathrm{m}$ focal steps. For each neuron in the image stack, the optical section in which it had the maximal projection was used to trace the soma boundary in NIH ImageJ. Somas crossing the boundaries of the image were excluded. For most soma size measurements in wild-type (WT) and null mice and for all the measurements in the HET mice, the sizes were measured blind to the WT or null expression of MeCP2.

\section{HPLC}

Freshly dissected pons and cortices were quick frozen on dry ice. Tissues were homogenized in $0.1 \mathrm{M}$ trichloroacetic acid containing $10 \mathrm{~mm}$ sodium acetate, $0.1 \mathrm{~mm}$ EDTA, and 10.5\% methanol, pH 3.8. Samples were spun in a microcentrifuge at $10,000 \times g$ for $20 \mathrm{~min}$. The supernatant was used for bioamine determination, and the pellet was saved for total protein quantification with the BCA Protein assay kit (Pierce). Bioamine levels were measured by HPLC at the Vanderbilt School of Medicine Neurochemistry Core (Nashville, TN) using an autosampler and a Decade II electrochemical detector. Data are presented as nanograms of bioamine per milligram of total protein.

All values are reported as mean \pm SEM. One-way and two-way ANOVAs were used to compare means of multiple levels of one or two factors, respectively and were followed by post hoc Tukey's test. Student's $t$ test was used to analyze data when only one parameter among two groups of animals was being compared.

\section{Results}

\section{LC neuron size is reduced in Mecp2 mutant mice}

Initial observations suggested that neurons of the LC region are smaller in null mice compared with WT controls. Therefore, we compared the soma size of LC neurons in male WT and null mice using confocal imaging of TH-labeled (THGFP mice or TH immunostained) brain sections. In addition, to determine whether or not changes in cell size are attributable to cell-autonomous effects 
A

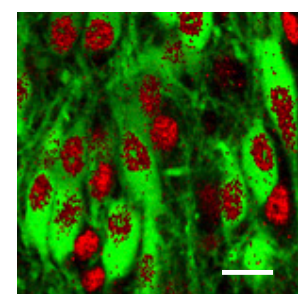

WT Female

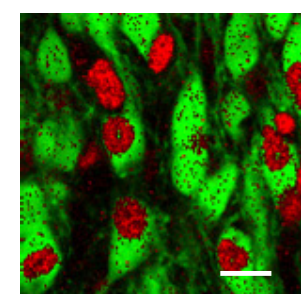

HET Female

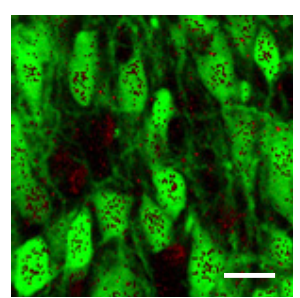

Null Male

$\mathrm{C}$
B

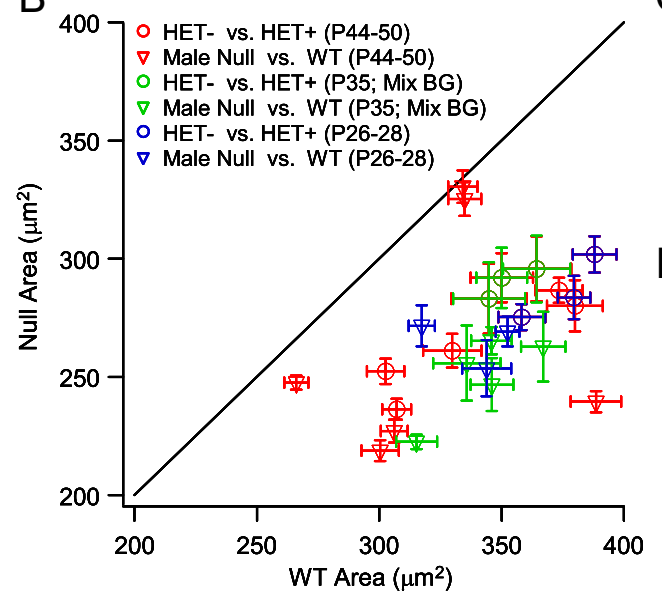

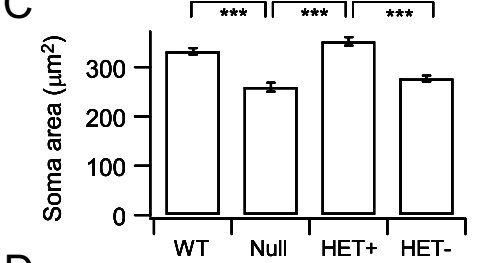

$D$

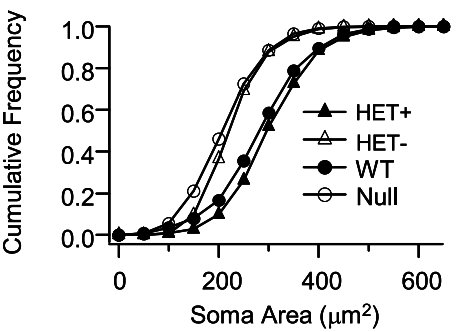

Figure 1. Cell-autonomous decrease in soma size of locus ceruleus neurons from null mice. $\boldsymbol{A}$, Representative confocal images of neurons from the locus ceruleus of a WT female, a HET female, and a null male THGFP mouse (GFP in green) immunostained with MeCP2 (red) antibody. Scale bars, $20 \mu \mathrm{m}$. The MeCP2 antibody stained the WT neurons but not the null neurons. In HET females, approximately half of the neurons were stained by the MeCP2 antibody in an apparently random pattern. $\boldsymbol{B}$, Average soma sizes of null (HET ${ }^{-}$for HET mice) versus WT (HET ${ }^{+}$for HET mice) neurons for different age groups and mixed genetic background. The diagonal represents the identity line along which null soma sizes are identical to WT soma sizes. In all pairs, null neurons are smaller than WT neurons. There is no significant effect of age (for P26-P50), genetic background, or gender (within neurons from WT mice) on soma size. Average $(\boldsymbol{C})$ and cumulative frequency distribution $(\boldsymbol{D})$ of soma sizes (pooled data including all age groups, pure/mixed genetic background, and male/female mice for WT). In HET mice, average soma size of HET ${ }^{-}$neurons is smaller than that of $\mathrm{HET}^{+}$neurons from the same animal (number of HET mice $=11$ ). The decrease is similar to the decrease in size of neurons from null mice $(n=14)$ compared with WT mice $(n=21)$. The size of HET ${ }^{-}$neurons from HET mice is similar to neurons from null male mice, whereas the size of HET ${ }^{+}$neurons from HET mice is similar to neurons from WT mice. BG, Background. ${ }^{* * *} p<0.001$, one-way ANOVA with post hoc Tukey's test.

of MeCP2 loss, we included in our analysis female HET mice, which are mosaic for WT MeCP2 $\left(\mathrm{HET}^{+}\right)$and null $\mathrm{MeCP} 2$ $\left(\mathrm{HET}^{-}\right)$expressing neurons. In WT female mice, all neurons were labeled by the MeCP2 antibody, whereas none of the neurons in the null male mice were labeled (Fig. $1 A$, THGFP mice with GFP in green). In the HET mice, $~ 50 \%$ of LC neurons were labeled with the MeCP2 antibody as expected, attributable to $\mathrm{X}$-chromosome inactivation (ratio of $\mathrm{HET}^{+}$neurons/HET ${ }^{-}$ neurons, $1: 1 \pm 0.1, n=11$ mice). Furthermore, we examined animals with different genetic backgrounds (C57BL/6 vs mixed sv129, BALB/c, C57BL/6) and different ages (P26-P50). Figure $1 B-D$ summarizes soma size measurements for each of the four categories of neurons analyzed (WT male/female, male null, $\mathrm{HET}^{+}$cells from HET mice, and $\mathrm{HET}^{-}$cells from HET mice). Six different comparisons of WT versus null neurons are shown in Figure $1 B$, including the following: (1) neurons from null mice versus WT mice (P44-P50; pure C57BL/6 background), (2) $\mathrm{HET}^{-}$versus $\mathrm{HET}^{+}$neurons from HET mice (P44-P50; pure C57BL/6 background), (3) neurons from null mice versus WT mice (P35; mixed genetic background), (4) $\mathrm{HET}^{-}$versus $\mathrm{HET}^{+}$ neurons from HET mice (P35; mixed genetic background), (5) neurons from null mice versus WT mice (P26-P28, the age used for electrophysiologic recordings; pure C57BL/6 background), and (6) $\mathrm{HET}^{-}$versus $\mathrm{HET}^{+}$neurons from HET mice (P26-P28; pure C57BL/6 background).

In all pairs, regardless of age or genetic background, Mecp2 null neurons are smaller than WT neurons (Fig. $1 B$ ). Soma size is not significantly different between different age groups ( $p_{\text {(WT: size vs }}$ age $=0.4, p_{\text {(null: size vs age) }}=0.8$; one-way ANOVA), genetic background ( $p_{\text {(WT: size vs }}$ background $)=0.3, p_{\text {(null: size vs background })}=$ 0.5 ) and, within WT, is not significantly different between male and female mice ( $p=0.4$; one-way ANOVA). The average soma sizes (pooled data including all age groups, male/female mice for WT, and pure/mixed genetic background; compared using one-way ANOVA with post hoc Tukey's test) and the corresponding cumulative size distributions are shown in Figure 1, $C$ and $D$, respectively. $\mathrm{HET}^{-}$LC neurons in HET mice are $22 \pm 4 \%$ smaller than $\mathrm{HET}^{+}$LC neurons in the same mice (soma area: $\mathrm{HET}^{+}, 353 \pm 9 \mu \mathrm{m}^{2}$ vs $\mathrm{HET}^{-}, 277 \pm 6 \mu \mathrm{m}^{2} ; n=11$ mice; $p<$ 0.001 ), just as neurons from null mice are $22 \pm 4 \%$ smaller than those from WT mice (soma area: WT, $332 \pm 6 \mu \mathrm{m}^{2}$ vs null, $260 \pm 9 \mu \mathrm{m}^{2} ; n=21$ mice for WT, $n=14$ mice for nulls; $p<0.001)$. Moreover, $\mathrm{HET}^{-}$and $\mathrm{HET}^{+}$neurons in HET mice are not significantly different in size from neurons in null $(p=0.45)$ and WT $(p=0.24)$ mice, respectively. Thus, we conclude that LC neuron size is determined by the cellular Mecp2 genotype in a cell-autonomous manner. In addition, the effects of MeCP2 loss on LC cell size are independent of age (for P26-P50), gender, and genetic background.

To rule out the possibility that our cell size measurements were influenced by potential differences in $\mathrm{TH}$ staining intensity (GFP or immunolabeling) among $\mathrm{HET}^{+}$and $\mathrm{HET}^{-}{ }^{-}$LC neurons, we also measured the soma sizes of LC neurons filled with biocytin (supplemental Fig. S1, available at www.jneurosci.org as supplemental material). The soma size of $\mathrm{HET}^{-}$neurons is reduced by $17 \pm 6 \%$ compared with $\mathrm{HET}^{+}$neurons $(p<0.01)$, comparable with the $22 \pm 4 \%$ decrease measured in TH-stained sections, indicating that cell size differences are not an artifact of the staining method.

\section{Electrophysiological properties}

The basic electrophysiological properties of WT LC neurons analyzed in this study are comparable with those reported previously in rat (Williams et al., 1984; Osmanović et al., 1990; Ishimatsu and Williams, 1996) and mouse (van den Pol et al., 2002). Nearly $75 \%$ of the recorded neurons were spontaneously active (spike frequency, $0.8 \pm 0.1 \mathrm{~Hz}$ ) even under conditions of synaptic blockade. The spike voltage threshold was $-29.4 \pm 0.6$ $\mathrm{mV}$, and each spike was followed by a pronounced AHP of $-24.4 \pm 0.7 \mathrm{mV}$. The membrane resistance measured at $-60 \mathrm{mV}$ was $430 \pm 30 \mathrm{M} \Omega$ under conditions of synaptic blockade and, similar to previous reports, $320 \pm 20 \mathrm{M} \Omega$ without synaptic block- 
ade $(p<0.01)$. In conditions of synaptic blockade, the resting membrane potential of LC neurons was significantly more hyperpolarized compared with that in absence of synaptic blockade (with synaptic blockade, $-49 \pm 1 \mathrm{mV}$ vs without synaptic blockade, $-43.1 \pm 0.7 \mathrm{mV} ; p<0.001$ ), suggesting that ongoing synaptic activity contributes to LC depolarization.

\section{Mecp2 null neurons are hyperexcitable}

To determine the effect of Mecp 2 mutation on the intrinsic excitability of LC neurons, we measured their FI curves during synaptic blockade, in isolated brain slice preparations from WT, HET, and null animals. Representative traces of repetitive firing of a WT and null neuron in response to current steps are shown in Figure 2, $A$ and $B$, respectively. The neuron from the null mouse fired at $\sim 40 \%$ greater frequency than the neuron from the WT mouse in response to the same injected current. This enhanced excitability is evident over a wide range of injected currents (Fig. 2C) and for all animals tested (number of mice: $\mathrm{WT}=6$, null $=4$; number of neurons: WT $=36$, null $=34$ ). To test whether the increase in intrinsic excitability is a cell-autonomous effect of Mecp2 mutation, we also measured the FI curves of LC neurons from female HET mice (number of mice: HET $=8$; number of neurons: $\mathrm{HET}^{+}=29$ HET $^{-}=21$ ). The recorded neurons were subsequently stained for biocytin and immunolabeled for $\mathrm{MeCP} 2$ to distinguish between WT or null expression of $\mathrm{MeCP} 2$. We found that $\mathrm{HET}^{-}$neurons also display a hyperexcit-

able phenotype, as described for null neurons, whereas the excitability profile of $\mathrm{HET}^{+}$neurons is similar to that of WT neurons (Fig. $2 C)$. The slopes of the FI curves calculated using a linear fit between $I=90$ and $300 \mathrm{pA}$ are shown in Figure 2D (compared using ANOVA with post hoc Tukey's test). The slopes for HET ${ }^{-}$and null neurons are significantly higher than the slopes for $\mathrm{HET}^{+}$and WT neurons, respectively (slope values, expressed as the number of spikes/pA: $\mathrm{HET}^{+}, 0.063 \pm 0.003$ vs $\mathrm{HET}^{-}, 0.092 \pm 0.006 ; p<$ 0.001 ; WT, $0.064 \pm 0.004$ vs null, $0.095 \pm 0.004 ; p<0.001)$. There is no significant difference between the slopes for $\mathrm{HET}^{-}$and null neurons $(p=0.77)$ or between $\mathrm{HET}^{+}$and WT neurons $(p=0.98)$, respectively. These data suggest that loss of $\mathrm{MeCP} 2$ causes a cellautonomous increase in the intrinsic excitability of LC neurons.

If membrane properties are otherwise similar, smaller neurons will respond to the same injected current with greater depolarization and greater firing frequency. To investigate the electrophysiological correlates of reduced size in MeCP2 null neurons, we compared their passive membrane properties with those of WT neurons in male and female HET mice. HET ${ }^{-}$neurons from HET female mice have a significantly lower membrane capacitance than $\mathrm{HET}^{+}$neurons (Fig. $2 \mathrm{E}: \mathrm{HET}^{+}, 127 \pm 5 \mathrm{pF}$ vs $\left.\mathrm{HET}^{-}, 93 \pm 4 \mathrm{pF} ; p<0.001\right)$, just as null neurons have a significantly lower capacitance than WT neurons (WT, $130 \pm 4 \mathrm{pF}$ vs null, $94 \pm 3 \mathrm{pF} ; p<0.001)$. There is no significant difference in capacitance between HET ${ }^{-}$and null neurons $(p=0.99)$ or between $\mathrm{HET}^{+}$and WT neurons $(p=0.97)$, respectively. The $28 \pm$ $5 \%$ decrease in capacitance in the neurons from null mice relative to WT is not significantly different from the $22 \pm 4 \%$ decrease in soma area measured using $\mathrm{TH}$ staining. $\mathrm{HET}^{-}$neurons have a significantly lower membrane conductance (measured at -60 $\mathrm{mV}$ ) compared with $\mathrm{HET}^{+}$neurons (Fig. $2 \mathrm{~F}: \mathrm{HET}^{+}, 2.9 \pm 0.2$ $\mathrm{nS}$ vs $\left.\mathrm{HET}^{-}, 2.3 \pm 0.2 \mathrm{nS} ; p<0.05\right)$. The conductance of null neurons also tends to be lower than that of WT neurons (WT, $2.6 \pm 0.2 \mathrm{nS}$ vs null, $2.27 \pm 0.09 \mathrm{nS}$ ), but this difference is not statistically significant ( $p=0.2$; one-way ANOVA with post hoc Tukey's test).

Similarly, increased excitability, reduced membrane conductance, and reduced capacitance is also observed in the absence of synaptic blockers, in null LC neurons compared with WT [performed on THGFP mice; percentage change: slope $=$ $60 \pm 10 \%$ increase $(p<0.001)$, capacitance $=25 \pm 4 \%$ decrease $(p<0.001)$, conductance $=21 \pm 9 \%$ decrease $(p=$ $0.052)$; number of mice: $\mathrm{WT}=3$, null $=4$; number of neurons: $\mathrm{WT}=16$, null $=17$ ].

Assuming that the firing frequency is linearly related to membrane voltage over the linear range of the FI curve, the increase in FI slope $(\sim 48 \%)$ can only partially be accounted for by the modest increase in membrane resistance $(\sim 15 \%$ for null neurons and 
A
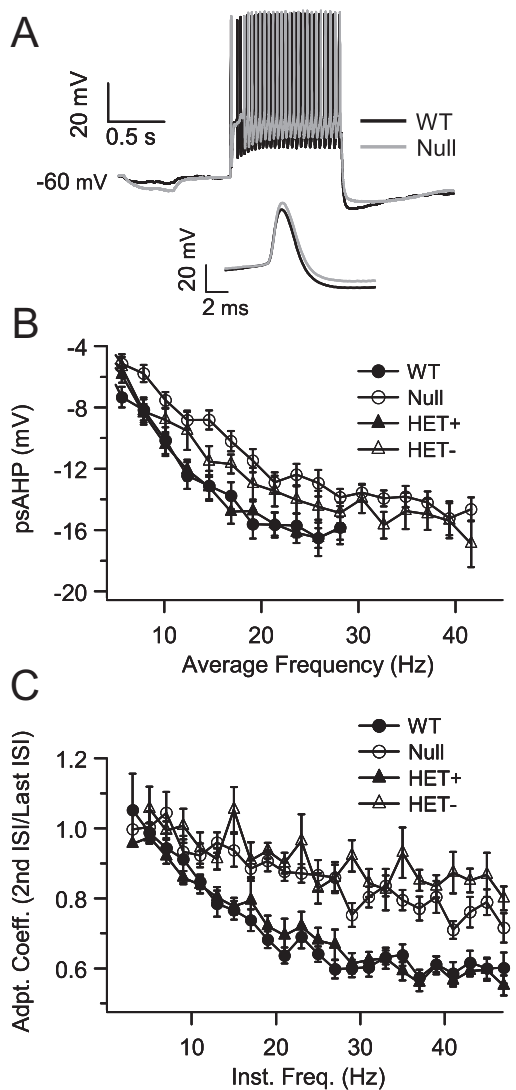

Figure 3. Neurons from the locus ceruleus of null mice have smaller psAHP and SFA compared with neurons from WT mice. $A$, Representative repetitive firing for neurons from WT and null mice at similar firing frequencies. Note the smaller psAHP in the recording from the null neuron. Inset, Single action potential at an extended timescale showing a slight increase in spike width in null neurons. $\boldsymbol{B}$, Average psAHP at different average frequencies for neurons from WT, null, and HET female mice showing that HET ${ }^{-}$neurons from HET mice have a smaller psAHP than that of $\mathrm{HET}^{+}$neurons $(p<0.01)$, just as the neurons from null mice have a smaller psAHP than that of WT neurons $(p<0.01)$. C, SFA coefficient (second ISI/last ISI) at different instantaneous firing frequencies (inverse of second ISI). HET $^{-}$neurons from HET mice have a higher SFA coefficient (i.e., lower adaptation) than $\mathrm{HET}^{+}$neurons $(p<0.01)$, just as neurons from null mice have a higher SFA coefficient than that of WT neurons $(p<0.01)$. Adpt. Coeff., Adaptation coefficient; Inst. Freq., instantaneous frequency. Differences were tested with twoway ANOVA and post hoc Tukey's test.

$26 \%$ for $\mathrm{HET}^{-}$neurons). In fact, the firing frequency of null neurons is higher than that of WT neurons even at the same average interspike voltage (supplemental Fig. S2, available at www. jneurosci.org as supplemental material: $p<0.01$, two-way ANOVA). Thus, it is possible that currents other than those that contribute to the passive membrane conductance are altered by Mecp2 mutation.

Mecp2 null neurons have a reduced spike frequency adaptation Neuronal excitability is dependent on the interplay between passive membrane properties and voltage-dependent conductances. LC neurons have prominent AHPs that build up during a spike train and recover slowly after a stimulus (Osmanović and Shefner, 1993). Figure $3 A$ shows representative repetitive firing (inset shows single action potential) at matched frequencies from WT and null mice. The neuron from the null mouse had a $21 \%$ smaller psAHP compared with that of the neuron from the WT mouse. At matched average firing frequencies, $\mathrm{HET}^{-}$neurons from HET mice have smaller psAHPs than $\mathrm{HET}^{+}$neurons (Fig. $3 B)(p<0.01)$ as do neurons from null mice compared with WT neurons $(p<0.01)$.
In many neuronal cell types, including LC neurons, multiple distinct components of the AHP (referred to as AAH, mAHP, and sAHP for fast, medium, and slow AHPs, respectively) can be distinguished (Osmanović et al., 1990; Velumian and Carlen, 1999; Abel et al., 2004; Villalobos et al., 2004). Typically, fAHP and $\mathrm{mAHP}$ contribute to the action potential amplitude, width, and hyperpolarization after single spikes, whereas the mAHP and sAHP contribute to spike frequency adaptation (SFA) and psAHP. In LC neurons, the psAHP consists of a faster early component resembling the $\mathrm{mAHP}$ in other neurons and a slower late component resembling the sAHP (Osmanović et al., 1990; Osmanović and Shefner, 1993). Accordingly, we observed two kinetically distinct components of the psAHP in our recordings corresponding to "medium" and "slow" AHPs. $\tau_{\text {med }}$ is similar to that reported previously (Osmanović et al., 1990) and does not significantly differ between WT and null neurons (WT, $240 \pm 30$ $\mathrm{ms}$ for $I=180 \mathrm{pA}$ and $f=10.5 \pm 0.7 \mathrm{~Hz}$ vs null, $260 \pm 30 \mathrm{~ms}$ for $I=120 \mathrm{pA}$ and $f=10.3 \pm 0.7 \mathrm{~Hz} ; p=0.72)$. The amplitude of this component evoked at moderate current injections also does not differ. The decay time constant of the sAHP, $\tau_{\text {slow }}$, is more than an order of magnitude longer but is not significantly different between WT and null neurons (WT, $8.5 \pm 0.6 \mathrm{~s}$ for $I=420 \mathrm{pA}$ and $f=26 \pm 1 \mathrm{~Hz}$ vs null, $8 \pm 1 \mathrm{~s}$ for $I=300 \mathrm{pA}$ and $f=27 \pm 2$ $\mathrm{Hz} ; p=0.6$ ). However, the amplitude of the sAHP (supplemental Fig. $\mathrm{S} 3 A$, available at www.jneurosci.org as supplemental material), $A_{\text {slow }}$, is significantly smaller for neurons from null mice than from WT mice (WT, $-7.2 \pm 0.4 \mathrm{mV}$ vs null, $-4.5 \pm 0.4$ $\mathrm{mV} ; p<0.001)$.

Because currents underlying mAHP and sAHP can regulate spike frequency adaptation (Pedarzani and Storm, 1993; Abel et al., 2004; Faber and Sah, 2005), a reduced sAHP could, in turn, decrease SFA and therefore contribute to the increased excitability we observe in Mecp2 null LC neurons. Figure 3C shows the adaptation coefficient (second ISI/last ISI) of WT, null, and HET LC neurons as a function of instantaneous firing frequency (inverse of second ISI). For all sets of neurons, the adaptation coefficient decreased from unity (unity equals no adaptation) as instantaneous firing frequency increased. However, for frequencies above $11 \mathrm{~Hz}$, the adaptation coefficient for $\mathrm{HET}^{-}$neurons is significantly higher than that of $\mathrm{HET}^{+}$neurons $(p<0.01)$, just as the adaptation coefficient of neurons from null neurons is higher than that for WT neurons $(p<0.01)$, indicating that loss of MeCP2 leads to reduced SFA.

In LC neurons, as in several other neuron types, the mAHP is mediated by SK channels, which are selectively blocked by the antagonist apamin (Osmanović et al., 1990; Pedarzani and Stocker, 2008). Moreover, apamin application increases the excitability and abolishes the psAHP of LC neurons. In our experiments, apamin (100 nM) completely abolishes the mAHP in WT and null neurons matched for the same baseline firing frequency (number of mice: $\mathrm{WT}=8$; null $=8$; number of neurons: WT $=$ 29; null = 32) but does not affect the sAHP (supplemental Fig. $\mathrm{S} 3 A$, available at www.jneurosci.org as supplemental material). However, the drug-sensitive hyperpolarization is not significantly different between WT and null mice (supplemental Fig. $\mathrm{S} 3 B$, available at www.jneurosci.org as supplemental material). Application of apamin also increases the excitability of both WT and null neurons (supplemental Fig. S3C, available at www. jneurosci.org as supplemental material), but the increase in firing frequency as a function of initial firing rate is not significantly different between the WT and null neurons (supplemental Fig. $\mathrm{S} 3 \mathrm{D}$, available at www.jneurosci.org as supplemental material). The spike width (measured as the time interval between voltage 
crossing of spike threshold on either side of the peak) of neurons from null mice is significantly higher $(p<0.01$, two-way ANOVA) than that of neurons from WT mice (supplemental Fig. S3E, available at www.jneurosci.org as supplemental material) (Fig. 3A, inset). However, application of apamin does not significantly affect the spike width of WT or null neurons. These results suggest that, although Mecp2 mutation alters currents underlying the sAHP, apamin-sensitive SK channels appear to be unaffected. The molecular identity of ion channel(s) mediating the sAHP is as yet unknown.

\section{Null mice exhibit a pontine and forebrain noradrenergic deficit}

Previous studies demonstrated that wholebrain concentrations of NE, dopamine, and serotonin are depressed in null mice after the fourth postnatal week (Ide et al., 2005). Therefore, to begin examining whether hyperexcitability and reduced size of Mecp2 null LC neurons are associated with altered noradrenergic function, we compared expression of TH in the LC, as well as pontine NE levels in 5-week-old (P35) WT, HET, and null mice. This analysis demonstrated significant decreases of $20 \pm 2 \%$ in the level of TH immunoreactivity in the LC as a whole $(n=5 \mathrm{WT}$ and 4 null mice; $p<0.01$, unpaired $t$ test $)$ and $19 \pm$ $2 \%$ in the cytoplasm of individual LC neurons ( $n=133$ neurons per group; $p<0.001$, unpaired $t$ test), in null mice compared with WT controls (Fig. 4A1,A2). Similarly, the intensity of TH staining is decreased by $21 \pm 2 \%$ in individual $\mathrm{HET}^{-}$cells compared with $\mathrm{HET}^{+}$cells in HET mice (Fig. $\left.4 B\right)(p<0.001$, unpaired $t$ test). In addition, $\mathrm{HET}^{+}$cells in the HET mice exhibit significantly lower levels of TH compared with cells in WT females (Fig. 4B) (19 $\pm 2 \%$ decrease in $\mathrm{HET}^{+}$cells compared with WT; $p<0.001$, unpaired $t$ test), indicating that $\mathrm{TH}$ expression in LC neurons may be regulated by $\mathrm{MeCP} 2$ through both cell-autonomous and non-autonomous mechanisms. Moreover, we found that the difference in TH levels between female WT and $\mathrm{HET}^{-}$LC neurons (Fig. 4B) (36 $\pm 2 \%$ decrease in $\mathrm{HET}^{-}$cells compared with WT) is much greater than that between male WT and null cells ( $\sim 20 \%$ decrease in null cells compared with WT), suggesting that $\mathrm{TH}$ regulation by $\mathrm{MeCP} 2$ may also be influenced by gender-specific factors.

Measurements of biogenic amine content using HPLC revealed a significant reduction in the levels of NE (normalized to total protein: $\mathrm{WT}=8.26 \pm 0.32 \mathrm{ng} / \mathrm{mg}$; null $=7.12 \pm 0.36$ ng/mg; $n=6$ mice per group; $p<0.05$, unpaired $t$ test), dihydroxyphenylacetic acid (WT $=0.94 \pm 0.06 \mathrm{ng} / \mathrm{mg}$; null $=0.50 \pm$ $0.10 \mathrm{ng} / \mathrm{mg} ; n=6$ mice per group; $p<0.01$, unpaired $t$ test $)$, and dopamine $(\mathrm{WT}=1.56 \pm 0.10 \mathrm{ng} / \mathrm{mg} ;$ null $=1.03 \pm 0.10 \mathrm{ng} / \mathrm{mg}$; $n=6$ mice per group; $p<0.01$, unpaired $t$ test) in the caudal pons of null mice compared with WT controls (Fig. 5). Although not specifically related to the LC, serotonin is also decreased in the pons of null mice (data not shown) (WT $=15.94 \pm 0.78 \mathrm{ng} / \mathrm{mg}$; null $=11.76 \pm 0.36 \mathrm{ng} / \mathrm{mg} ; n=6$ mice per group; $p<0.001$, unpaired $t$ test).

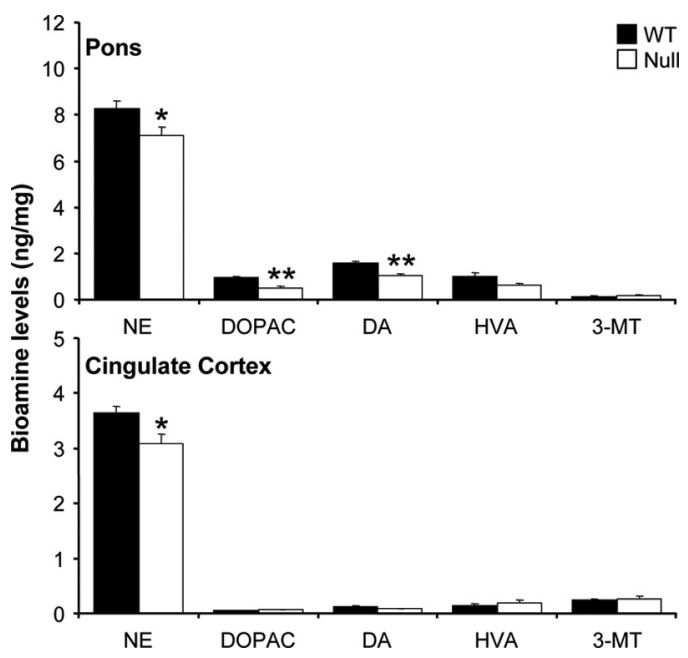

Figure 5. Biogenic amine content is significantly decreased in the pons and cingulate cortex of P35 null mice. HPLC analysis of bioamine levels in pons and cingulate cortex samples from WT (black bars) and null (white bars) mice. $n=6$ mice; ${ }^{*} p<0.05,{ }^{* *} p<$ 0.01, unpaired $t$ test. DOPAC, Dihydroxyphenylacetic acid; DA, dopamine; HVA, homovanillic acid; 3MT, 3-methoxytyramine.

To begin examining the possibility that LC defects may affect noradrenergic innervation of distal brain regions, we compared TH and NE levels in the cingulate cortex, a forebrain target of LC, in P35 WT and null mice (Fig. 4C1,C2). In normal animals, the cingulate cortex is densely innervated by $\mathrm{TH}$-positive neuronal processes, a subset of which is derived from the LC, and noradrenergic innervation of the cingulate cortex is derived entirely from the LC. Densitometric analysis of TH immunostained sec- 
tions demonstrated a significant $29 \pm 8 \%$ decrease in $\mathrm{TH}$ positive fiber density in the cingulate cortex of null mice compared with WT mice ( $n=3$ mice per group; $p<0.05$, unpaired $t$ test) (Fig. 4C1,C2). In addition, the level of NE is significantly decreased in the cingulate cortex of null mice compared with WT controls (Fig. 5) (normalized to total protein, WT = $3.65 \pm 0.12 \mathrm{ng} / \mathrm{mg}$; null $=3.08 \pm 0.17 \mathrm{ng} / \mathrm{mg} ; n=6$ mice per group; $p<0.05$, unpaired $t$ test). These deficits cannot be accounted for by a loss of LC neurons, because we found no difference in the number of TH-positive LC neurons between null and $\mathrm{WT}$ mice $(\mathrm{WT}=2128 \pm 72$ neurons; null $=2237 \pm 129$ neurons; number of mice: $\mathrm{WT}=3$, null $=3 ; p=0.51$, unpaired $t$ test).

\section{Discussion}

Our results demonstrate that genetic loss of $\mathrm{MeCP} 2$ results in marked alterations in morphological, electrical, and neurochemical properties of LC neurons in mice, including decreased soma size, membrane conductance, and sAHP amplitude, as well as increased excitability. In addition, we found that the TH content of Mecp2 null LC neurons is reduced, along with pontine NE levels and noradrenergic innervation of the cingulate cortex, a forebrain target of the LC. Thus, the Mecp 2 null LC phenotype is somewhat paradoxical, in that the intrinsic excitability of mutant neurons is increased, whereas noradrenergic expression and target innervation are decreased.

\section{Mecp 2 mutation results in cell-autonomous and non-autonomous changes in LC neuron properties}

Because $\mathrm{MeCP} 2$ is expressed throughout the brain during postnatal development (Kishi and Macklis, 2004), we examined whether the effects of Mecp2 mutation are attributable to extrinsic (network or systemic) or intrinsic (cell-autonomous) influences. To address this question in LC neurons, we asked whether their cellular phenotype reflects the genotype of individual neurons or the animal as a whole by comparing soma size, electrical properties, and TH expression, not only in WT and null mice but also in HET mice that are mosaic for $\mathrm{HET}^{+}$and $\mathrm{HET}^{-}$neurons. In HET mice, neurons lacking MeCP2 are smaller than neurons that express $\mathrm{MeCP} 2$, and this difference is nearly identical to the difference between neurons from WT and null mice. The same is true for intrinsic neuronal excitability. Thus, the factors responsible for reduced neuronal size and hyperexcitability in mutant LC neurons appear to be cell-autonomous. It should be noted that our definition of cell-autonomous effects does not preclude mechanisms that require intercellular signaling (such as responsiveness to neurotrophic factors); however, it requires that these mechanisms be dependent on whether or not the cell expresses $\mathrm{MeCP} 2$. In contrast, $\mathrm{HET}^{+}$neurons express less $\mathrm{TH}$ than WT cells, indicating both cell-autonomous and extrinsic influences on the noradrenergic phenotype of LC neurons.

Mecp2 mutation increases intrinsic excitability of LC neurons We found previously that network excitability is decreased in the neocortex of young, early-symptomatic Mecp2 null mice with no change in intrinsic neuronal excitability (Dani et al., 2005). Rather, this decrease reflects reduced excitatory and increased inhibitory synaptic input to cortical neurons. Changes in synaptic transmission have also been reported in hippocampus (Moretti et al., 2006; Chao et al., 2007) and brainstem (Medrihan et al., 2008), but none of these previous studies have reported changes in intrinsic membrane properties. The present study reveals that reduced cell size and membrane conductance are associated with enhanced excitability of $\mathrm{HET}^{-}$LC neurons in HET and null animals [linear correlation coefficient $(r)$ between slope of FI curve and inverse of capacitance: WT, $0.5 \pm 0.1, p_{(r=0)}<0.01$; null, $\left.0.3 \pm 0.2, p_{(r=0)}=0.06\right]$. The decreased conductance is attributable, at least in part, to a decrease in neuronal membrane area (smaller capacitance). Although several studies have reported reduced neuronal size and dendritic arborization in RTT patients (Belichenko et al., 1994; Armstrong et al., 1995; Bauman et al., 1995) and Mecp2 mutant mice (Chen et al., 2001; Kishi and Macklis, 2004), we previously found only modestly reduced membrane conductance in cortical neurons from 4- to 5-weekold Mecp2 null mice (Dani et al., 2005). We suspect that LC neurons are more severely affected by loss of MeCP2 than other populations studied thus far and that the increase in intrinsic excitability reported here reflects a more pronounced decrease in soma size.

Although we did not explicitly measure changes in synaptic inputs to LC neurons, the fact that we observed similarly increased excitability and reduced membrane capacitance and conductance without synaptic blockade suggests that changes in synaptic inputs, if present, are too subtle to significantly alter the observed hyperexcitability of Mecp2 null neurons.

We also identified a decreased sAHP and correspondingly reduced SFA as factors contributing to the hyperexcitability of Mecp2 null LC neurons. The psAHP in LC neurons seems to be composed of two components that likely correspond to the mAHP and sAHP that have been observed in other neurons (Velumian and Carlen, 1999; Abel et al., 2004; Villalobos et al., 2004). Although the amplitude of the sAHP is significantly smaller in neurons from null mice, the amplitude of the mAHP is not different. Application of apamin caused the same increase in excitability and decrease in the faster component of the psAHP in both WT and null LC neurons, suggesting that Mecp2 mutation only affects currents underlying the sAHP but not the mAHP. The decreased sAHP could reflect alterations in the expression or modulation of the underlying potassium currents, in calcium influx, or in the accumulation or buffering of intracellular calcium.

\section{Physiologic consequences of LC neuron dysfunction in Mecp2 mutant mice}

Noradrenergic inputs from LC regulate excitability of brainstem and cortical networks. In the brainstem, for example, LC inputs to rhythmically active respiratory neurons in the preBotzinger complex stimulate inspiration by excitatory actions at $\alpha 1$ receptors (Funk et al., 1994; Adachi et al., 2005). In addition, however, LC neurons themselves are sensitive to chemical respiratory drives, such as elevated $\mathrm{CO}_{2}$ (Biancardi et al., 2008; Johnson et al., 2008). Therefore, one consequence of LC neuron hyperexcitability may be destabilization of the respiratory rhythm, resulting from abnormal responses to elevated $\mathrm{CO}_{2}$. Indeed, respiratory instability, including periods of hyperventilation, is a hallmark of RTT (Glaze et al., 1987), although the specific role of LC dysfunction in the breathing phenotype has not yet been examined. More generally, reduced conductance could cause the LC neurons to become more sensitive to both excitatory and inhibitory synaptic inputs. This could result in larger fluctuations in NE release and consequently disturbances in noradrenergic modulation of LC neuron targets.

Conversely, indices of noradrenergic function, including $\mathrm{TH}$ and NE levels, are reduced in Mecp2 null LC neurons and in at least one LC target, the cingulate cortex. Reduced monoaminergic neurotransmission has long been postulated to contribute to 
the etiology of RTT. Initial studies reported that levels of NE, serotonin, and their metabolites or synthesizing enzymes are decreased in postmortem brain tissues from RTT patients (Riederer et al., 1985; Brücke et al., 1987; Lekman et al., 1989; Saito et al., 2001). Postnatal declines in NE, dopamine, and serotonin have also been noted in the brainstem of null mice (Ide et al., 2005) and have been associated with reduced numbers of $\mathrm{TH}$-expressing neurons in the $\mathrm{A} 1 / \mathrm{C} 1$ and $\mathrm{A} 2 / \mathrm{C} 2$ cell groups (Viemari et al., 2005; Roux et al., 2007). The present study identifies the LC as another brainstem site at which TH expression is reduced in null mice, consistent with postmortem findings in a human case of RTT (Saito et al., 2001). However, dysregulation of TH expression in the absence of MeCP2 is complex and appears to involve both cell-autonomous and extrinsic mechanisms. Thus, both $\mathrm{HET}^{+}$ and $\mathrm{HET}^{-}$cells in female HET mice express lower levels of TH protein than cells in WT females, although the $\mathrm{HET}^{-}$cells are more severely affected.

The LC is the major noradrenergic cell group in the pons and the only source of noradrenergic innervation to cingulate cortex, and we find that both areas exhibit reduced levels of NE in null mice by 5 weeks of age. Although we do not yet know whether these decreases in NE reflect reduced LC projections, reduced synthesis of NE, or both, these data indicate that pathophysiologic changes in null LC neurons are likely to affect noradrenergic signaling in both the brainstem and forebrain. Reduced brainstem NE has already been linked to respiratory dysfunction in null mice (Viemari et al., 2005). Reduced noradrenergic signaling in the cingulate cortex (and associated prelimbic cortices) in rodents is associated with deficits in cognitive function, including impairments of learning and memory (Sparenborg and Gabriel, 1992; Collier et al., 2004; Tait et al., 2007). NE potentiates synaptic plasticity in multiple forebrain regions, including amygdala (Tully et al., 2007), hippocampus (Hu et al., 2007), and neocortex (Seol et al., 2007), raising the possibility that reduced noradrenergic innervation of cingulate cortex in null mice, described here, may also lead to cognitive dysfunction. Moreover, NE regulates excitability of cortical networks and can elevate the threshold for seizures (Bengzon et al., 1999). Null mice, as well as RTT patients, are prone to seizures, and it is tempting to speculate that reduced cortical NE may be a contributing factor. However, the question remains how, and under what circumstances, the interplay between intrinsic hyperexcitability on the one hand and reduced expression of noradrenergic traits on the other actually influences LC function in Mecp2 mutants and, by implication, RTT patients.

Together, our results identify multiple deficits in Mecp2 null LC neurons, at least some of which are cell-autonomous consequences of the mutation. Because these neurons are a pivotal source of NE throughout the brainstem and forebrain and are involved in the regulation of diverse functions disrupted in RTT, such as respiration and cognition, we hypothesize that the LC is a critical site at which loss of MeCP2 results in CNS dysfunction. Restoration of normal LC function may therefore be of potential therapeutic value in the treatment of RTT.

\section{References}

Abel HJ, Lee JC, Callaway JC, Foehring RC (2004) Relationships between intracellular calcium and afterhyperpolarizations in neocortical pyramidal neurons. J Neurophysiol 91:324-335.

Adachi T, Robinson DM, Miles GB, Funk GD (2005) Noradrenergic modulation of XII motoneuron inspiratory activity does not involve alpha2receptor inhibition of the Ih current or presynaptic glutamate release. J Appl Physiol 98:1297-1308.
Amir RE, Van den Veyver IB, Wan M, Tran CQ, Francke U, Zoghbi HY (1999) Rett syndrome is caused by mutations in X-linked MECP2, encoding methyl-CpG-binding protein 2. Nat Genet 23:185-188.

Armstrong D, Dunn JK, Antalffy B, Trivedi R (1995) Selective dendritic alterations in the cortex of Rett syndrome. J Neuropathol Exp Neurol 54:195-201.

Bauman ML, Kemper TL, Arin DM (1995) Pervasive neuroanatomic abnormalities of the brain in three cases of Rett's syndrome. Neurology 45:1581-1586.

Belichenko PV, Oldfors A, Hagberg B, Dahlström A (1994) Rett syndrome: 3-D confocal microscopy of cortical pyramidal dendrites and afferents. Neuroreport 5:1509-1513.

Bengzon J, Hansson SR, Hoffman BJ, Lindvall O (1999) Regulation of norepinephrine transporter and tyrosine hydroxylase mRNAs after kainic acid-induced seizures. Brain Res 842:239-242.

Berridge CW, Waterhouse BD (2003) The locus coeruleus-noradrenergic system: modulation of behavioral state and state-dependent cognitive processes. Brain Res Brain Res Rev 42:33-84.

Biancardi V, Bícego KC, Almeida MC, Gargaglioni LH (2008) Locus coeruleus noradrenergic neurons and $\mathrm{CO} 2$ drive to breathing. Pflugers Arch 455:1119-1128.

Brücke T, Sofic E, Killian W, Rett A, Riederer P (1987) Reduced concentrations and increased metabolism of biogenic amines in a single case of Rett-syndrome: a postmortem brain study. J Neural Transm 68:315-324.

Chahrour M, Zoghbi HY (2007) The story of Rett syndrome: from clinic to neurobiology. Neuron 56:422-437.

Chao HT, Zoghbi HY, Rosenmund C (2007) MeCP2 controls excitatory synaptic strength by regulating glutamatergic synapse number. Neuron 56:58-65.

Chen RZ, Akbarian S, Tudor M, Jaenisch R (2001) Deficiency of methylCpG binding protein-2 in CNS neurons results in a Rett-like phenotype in mice. Nat Genet 27:327-331.

Collier TJ, Greene JG, Felten DL, Stevens SY, Collier KS (2004) Reduced cortical noradrenergic neurotransmission is associated with increased neophobia and impaired spatial memory in aged rats. Neurobiol Aging 25:209-221.

Dani VS, Chang Q, Maffei A, Turrigiano GG, Jaenisch R, Nelson SB (2005) Reduced cortical activity due to a shift in the balance between excitation and inhibition in a mouse model of Rett syndrome. Proc Natl Acad Sci U S A 102:12560-12565.

Faber ES, Sah P (2005) Independent roles of calcium and voltage-dependent potassium currents in controlling spike frequency adaptation in lateral amygdala pyramidal neurons. Eur J Neurosci 22:1627-1635.

Funk GD, Smith JC, Feldman JL (1994) Development of thyrotropinreleasing hormone and norepinephrine potentiation of inspiratoryrelated hypoglossal motoneuron discharge in neonatal and juvenile mice in vitro. J Neurophysiol 72:2538-2541.

Gelinas JN, Nguyen PV (2005) beta-adrenergic receptor activation facilitates induction of a protein synthesis-dependent late phase of long-term potentiation. J Neurosci 25:3294-3303.

Glaze DG, Frost JD Jr, Zoghbi HY, Percy AK (1987) Rett's syndrome: characterization of respiratory patterns and sleep. Ann Neurol 21:377-382.

Hagberg B, Aicardi J, Dias K, Ramos O (1983) A progressive syndrome of autism, dementia, ataxia, and loss of purposeful hand use in girls: Rett's syndrome: report of 35 cases. Ann Neurol 14:471-479.

Hu H, Real E, Takamiya K, Kang MG, Ledoux J, Huganir RL, Malinow R (2007) Emotion enhances learning via norepinephrine regulation of AMPA-receptor trafficking. Cell 131:160-173.

Ide S, Itoh M, Goto Y (2005) Defect in normal developmental increase of the brain biogenic amine concentrations in the HET - null mouse. Neurosci Lett 386:14-17.

Ishimatsu M, Williams JT (1996) Synchronous activity in locus coeruleus results from dendritic interactions in pericoerulear regions. J Neurosci 16:5196-5204.

Johnson SM, Haxhiu MA, Richerson GB (2008) GFP-expressing locus ceruleus neurons from Prp57 transgenic mice exhibit $\mathrm{CO} 2 / \mathrm{H}^{+}$responses in primary cell culture. J Appl Physiol 105:1301-1311.

Kishi N, Macklis JD (2004) MECP2 is progressively expressed in postmigratory neurons and is involved in neuronal maturation rather than cell fate decisions. Mol Cell Neurosci 27:306-321.

Lekman A, Witt-Engerström I, Gottfries J, Hagberg BA, Percy AK, Svenner- 
holm L (1989) Rett syndrome: biogenic amines and metabolites in postmortem brain. Pediatr Neurol 5:357-362.

Matsushita N, Okada H, Yasoshima Y, Takahashi K, Kiuchi K, Kobayashi K (2002) Dynamics of tyrosine hydroxylase promoter activity during midbrain dopaminergic neuron development. J Neurochem 82:295-304.

Medrihan L, Tantalaki E, Aramuni G, Sargsyan V, Dudanova I, Missler M, Zhang W (2008) Early defects of GABAergic synapses in the brain stem of a MeCP2 mouse model of Rett syndrome. J Neurophysiol 99:112-121.

Mehler MF, Purpura DP (2009) Autism, fever, epigenetics and the locus coeruleus. Brain Res Rev 59:388-392.

Moretti P, Levenson JM, Battaglia F, Atkinson R, Teague R, Antalffy B, Armstrong D, Arancio O, Sweatt JD, Zoghbi HY (2006) Learning and memory and synaptic plasticity are impaired in a mouse model of Rett syndrome. J Neurosci 26:319-327.

Ogier M, Katz DM (2008) Breathing dysfunction in Rett syndrome: understanding epigenetic regulation of the respiratory network. Respir Physiol Neurobiol 164:55-63.

Osmanović SS, Shefner SA (1993) Calcium-activated hyperpolarizations in rat locus coeruleus neurons in vitro. J Physiol 469:89-109.

Osmanović SS, Shefner SA, Brodie MS (1990) Functional significance of the apamin-sensitive conductance in rat locus coeruleus neurons. Brain Res 530:283-289.

Paxinos G, Franklin K (2001) The mouse brain in stereotaxic coordinates. San Diego: Academic.

Pedarzani P, Stocker M (2008) Molecular and cellular basis of small-and intermediate-conductance, calcium-activated potassium channel function in the brain. Cell Mol Life Sci 65:3196-3217.

Pedarzani P, Storm JF (1993) PKA mediates the effects of monoamine transmitters on the $\mathrm{K}^{+}$current underlying the slow spike frequency adaptation in hippocampal neurons. Neuron 11:1023-1035.

Riederer P, Brücke T, Sofic E, Kienzl E, Schnecker K, Schay V, Kruzik P, Killian W, Rett A (1985) Neurochemical aspects of the Rett syndrome. Brain Dev 7:351-360.

Roux JC, Dura E, Moncla A, Mancini J, Villard L (2007) Treatment with desipramine improves breathing and survival in a mouse model for Rett syndrome. Eur J Neurosci 25:1915-1922.

Saito Y, Ito M, Ozawa Y, Matsuishi T, Hamano K, Takashima S (2001) Re- duced expression of neuropeptides can be related to respiratory disturbances in Rett syndrome. Brain Dev 23 [Suppl 1]:S122-S126.

Schüle B, Armstrong DD, Vogel H, Oviedo A, Francke U (2008) Severe congenital encephalopathy caused by MECP2 null mutations in males: central hypoxia and reduced neuronal dendritic structure. Clin Genet $74: 116-126$.

Seol GH, Ziburkus J, Huang S, Song L, Kim IT, Takamiya K, Huganir RL, Lee HK, Kirkwood A (2007) Neuromodulators control the polarity of spiketiming-dependent synaptic plasticity. Neuron 55:919-929.

Sparenborg S, Gabriel M (1992) Local norepinephrine depletion and learning-related neuronal activity in cingulate cortex and anterior thalamus of rabbits. Exp Brain Res 92:267-285.

Tait DS, Brown VJ, Farovik A, Theobald DE, Dalley JW, Robbins TW (2007) Lesions of the dorsal noradrenergic bundle impair attentional set-shifting in the rat. Eur J Neurosci 25:3719-3724.

Tully K, Li Y, Tsvetkov E, Bolshakov VY (2007) Norepinephrine enables the induction of associative long-term potentiation at thalamo-amygdala synapses. Proc Natl Acad Sci U S A 104:14146-14150.

van den Pol AN, Ghosh PK, Liu RJ, Li Y, Aghajanian GK, Gao XB (2002) Hypocretin (orexin) enhances neuron activity and cell synchrony in developing mouse GFP-expressing locus coeruleus. J Physiol 541:169-185.

Velumian AA, Carlen PL (1999) Differential control of three afterhyperpolarizations in rat hippocampal neurones by intracellular calcium buffering. J Physiol 517:201-216.

Viemari JC, Roux JC, Tryba AK, Saywell V, Burnet H, Peña F, Zanella S, Bévengut M, Barthelemy-Requin M, Herzing LB, Moncla A, Mancini J, Ramirez JM, Villard L, Hilaire G (2005) Mecp2 deficiency disrupts norepinephrine and respiratory systems in mice. J Neurosci 25:11521-11530.

Villalobos C, Shakkottai VG, Chandy KG, Michelhaugh SK, Andrade R (2004) SKCa channels mediate the medium but not the slow calciumactivated afterhyperpolarization in cortical neurons. J Neurosci 24:35373542.

Williams JT, North RA, Shefner SA, Nishi S, Egan TM (1984) Membrane properties of rat locus coeruleus neurones. Neuroscience 13:137-156.

Zoghbi HY, Milstien S, Butler IJ, Smith EO, Kaufman S, Glaze DG, Percy AK (1989) Cerebrospinal fluid biogenic amines and biopterin in Rett syndrome. Ann Neurol 25:56-60. 